\section{Retinal vascular changes following intravitreal ranibizumab injections for neovascular AMD over a 1-year period}

${ }^{1}$ Centre for Eye Research Australia, University of Melbourne, Royal Victorian Eye and Ear Hospital, Melbourne, Victoria, Australia

${ }^{2}$ Singapore Eye Research Institute, National University of Singapore, Singapore, Singapore

Correspondence: TY Wong, Centre for Eye Research Australia, University of Melbourne, Royal Victorian Eye and Ear Hospital, 32 Gisborne Street, Melbourne 3002, Victoria, Australia Tel: + 613 99298352; Fax: + 61399298164 Email: twong@unimelb. edu.au

Received: 11 October 2011 Accepted in revised form: 13 March 2012 Published online: 4 May 2012

\begin{abstract}
Purpose To assess retinal vascular calibre changes in eyes with neovascular age-related macular degeneration (AMD), treated with intravitreal anti-vascular endothelial growth factor agents, over a 1-year period and compare any such changes to untreated fellow eyes.

Methods Treatment naïve patients with neovascular AMD received three consecutive intravitreal injections of ranibizumab, followed by a pro re nata dosing regimen up to 1 year, with the aim of maintaining a 'fluid-free' macula. Retinal arteriolar and venular calibre was measured from digital fundus photographs at baseline and at three monthly intervals to 1 year, and summarised as central retinal artery equivalent (CRAE) and central retinal venular equivalent (CRVE), respectively.

Results A total of 53 injected eyes and 41 fellow, non-injected eyes were analysed. At baseline, there were no differences in retinal vascular calibre between injected and non-injected eyes (mean CRAE (SD) 144.93 (14.07) vs 145.74 (13.10) $\mu \mathrm{m}, P=0.80$ and mean CRVE (SD) 216.23 (25.93) vs 219.91 (22.82) $\mu \mathrm{m}$, $P=0.53)$. Over a 12-month period, retinal venular calibre dilatation occurred in injected eyes (mean CRVE change +5.71 (14.71) $\mu \mathrm{m}$, $P=0.007)$, with no change in retinal arterioles, +0.69 (14.71) $\mu \mathrm{m}, P=0.68$. In noninjected eyes, arteriolar narrowing occurred as a whole, mean CRAE change -4.20 (7.00) $\mu \mathrm{m}, P=0.001$, over 12 months, with a trend for narrowing in venules, -2.16 (11.56) $\mu \mathrm{m}, P=0.28$. In injected eyes, after controlling for covariates, the changes in
\end{abstract}

SS Wickremasinghe', J Xie', RH Guymer', TY Wong ${ }^{1,2}$, R Kawasaki' and S Qureshi'

CRVE over 12 months mirrored improvements in macular thickness, $-0.06(-0.005$, $-0.11) \mu \mathrm{m}, P=0.04$, and visual acuity, +9.66 $(-0.30,+19.32) \mu \mathrm{m}, P=0.06$.

Conclusion Intravitreal ranibizumab significantly dilated retinal venules after a 1-year period.

Eye (2012) 26, 958-966; doi:10.1038/eye.2012.72; published online 4 May 2012

Keywords: AMD; retinal vasculature; anti-VEGF

Introduction

In neovascular age-related macular degeneration (AMD), choroidal neovascularisation (CNV) has been associated with ischaemic changes in the choroid, with increasing levels of correlating severity of $\mathrm{AMD}, 1,2$ as well as an overexpression of vascular endothelial growth factor (VEGF). ${ }^{3}$ Anti-VEGF drugs have significantly improved the treatment of individuals with neovascular AMD. ${ }^{4,5}$ However, there are concerns with the use of these drugs. VEGF is widely expressed in the normal retina and as well as in various organs, such as the heart, lungs, and kidneys, where several roles for the cytokine have been identified. Systemic administration of anti-VEGF agents has been linked to the development of complications such as, hypertension, retinal arterial vasoconstriction, thromboembolism, haemorrhage, proteinuria, and intestinal perforation. ${ }^{6-10}$ Despite local, ocular delivery in the treatment of neovascular AMD, little is known as to the potential 
beneficial or deleterious vasoactive effects of these compounds.

To date, there are only a limited number of studies assessing retinal vasculature changes in the setting of anti-VEGF use for neovascular AMD. Papadopoulou et $a l^{10}$ found a significant constriction of the retinal arterioles in 11 eyes treated with ranibizumab for neovascular AMD. They suggested that this was due to a reduction in nitric oxide-induced vasodilatation, with a subsequent reduction in retinal blood flow. The same group further reported the 1-year follow-up data and found similar results with significant retinal arteriolar constriction following treatment. ${ }^{11}$ A more recent study on 23 patients also found decreased retinal arteriolar diameter during the course of initial anti-VEGF injections for neovascular AMD. ${ }^{12}$ No significant change in blood flow was observed. All these studies, however, were limited by a lack of a control group.

Retinal vascular calibre is an indirect indicator of ocular blood flow and can be measured from photographs. ${ }^{13}$ Changes in retinal vascular calibre have been linked with systemic and ocular diseases and may reflect changes in blood flow, inflammation, and endothelial function. ${ }^{14,15}$ The aim of this study was to assess the response of the retinal vasculature to on-going VEGF blockade, over a 1-year period and determine if any changes were related to potential harmful or beneficial effects of this class of drugs.

\section{Materials and methods}

\section{Study population}

We performed a prospective study evaluating intravitreal ranibizumab on patients with CNV secondary to AMD. This research was approved by the Research and Ethics committee of the Royal Victorian Eye and Ear Hospital and followed the tenets of the Declaration of Helsinki.

Patients were recruited consecutively (1 January 2008-31 December 2008) from the retina clinics of the Royal Victorian Eye and Ear Hospital in Melbourne, Victoria, Australia. The inclusion criteria for this study were eyes with subfoveal CNV secondary to AMD that were deemed suitable for treatment with an anti-VEGF drug.

Over the study period, all the eyes with neovascular AMD that were treatment naïve were considered for inclusion as injected eyes, unless media opacity or mobility issues prevented adequate fundus visualisation and in the view of the examiner would prevent adequate fundus photography (these were excluded). Both eyes could be considered as injected eyes if bilateral CNV was present at the time of diagnosis. Fellow eyes not receiving active treatment were defined as non-injected eyes and characterised into two subgroups to allow assessment of the possible contribution that the $\mathrm{AMD} /$ macular pathology might have on the retinal vessel calibre, independent of active anti-VEGF treatment. The first group consisted of those patients with only features of early AMD (drusen, pigment epithelial hyper, or hypopigmentation). The second group consisted of those patients with pre-existing advanced or end-stage AMD (eg disciform scars). This group did not receive any active ocular treatment during the course of the study. Fellow eyes already receiving anti-VEGF treatment at the time of injected eye enrolment were excluded, as they were deemed to be similar to injected eyes.

\section{Measurement of retinal vascular calibre}

All the participants had fundus photography performed using a standardised protocol according to the MultiEthnic Study of Atherosclerosis. ${ }^{16}$ An optic disc-centred photograph was taken of each eye at baseline and at 3 months in all the participants (Early Treatment of Diabetic Retinopathy Study (ETDRS) Field 1). ${ }^{17}$ All photographs were taken prior to any treatment, using the $35^{\circ}$ setting of the Topcon fundus camera, TRC50 EX (Tokyo, Japan). At baseline, the photographs were taken within $48 \mathrm{~h}$ of the first treatment. For each subsequent visit, photographs were taken prior to any treatment given, if required.

Retinal vascular calibre was measured using a computer-based programme (IVAN, University of Wisconsin, Madison, WI, USA), based on a previously established protocol. ${ }^{18,19}$ A trained masked grader performed these measurements. Because of the disc centration of photographs, the macula status was not visible to the grader. For each photograph, all the arterioles and venules coursing through an area of onehalf to one-disc diameter from the optic disc margin were measured and vessel calibres of the biggest six were summarised as the central retinal artery equivalent (CRAE) and central retinal vein equivalent (CRVE) using formulas developed by Hubbard et al ${ }^{18}$ and later modified by Knudtson et al. ${ }^{20}$

\section{Visual acuity and macular thickness}

Visual acuity and central macular thickness (CMT) were measured at baseline and at 12 months by examiners masked to vessel measurements and to the treatments administered. Best-corrected logarithm of the minimal angle of resolution (Log MAR) visual acuity was performed using Early Treatment of Diabetic Retinopathy Study charts. CMT was measured with 
a Stratus OCT 3 (Zeiss-Humphrey Inc., San Leandro, CA, USA).

\section{Treatment and retreatment protocols}

Three 'loading dose' injections were given a monthly intervals using a standard protocol as previously described. ${ }^{21}$ In all cases, $0.05 \mathrm{ml}$ of ranibizumab $(0.5 \mathrm{mg})$, Novartis Pharmaceuticals, Sydney, New South Wales, Australia) was injected through the pars plana into the vitreous cavity using a 30-gauge needle. Following the initial 'loading' phase, repeat treatments were performed on a pro re nata basis, if there was any reduction in vision or increase in sub/ intraretinal fluid or haemorrhage, similar to the protocols used in the SUSTAIN ${ }^{22}$ and PRONTO $^{23}$ studies.

\section{Injection procedure}

The procedure for injection followed a standard protocol as previously described. ${ }^{21}$ In brief, eyes were prepared with several drops of amethocaine $1 \%$ and two drops of $5 \%$ povidone iodine. A lid speculum was used in all cases. A total of $2 \%$ lignocaine was then administered sub-conjunctivally to the site of the intravitreal injection. Using a 30-gauge needle, $0.05 \mathrm{ml}$ of ranibizumab $(0.5 \mathrm{mg})$ (Novartis Pharmaceuticals) was injected through the pars plana into the vitreous cavity. Chloramphenicol ointment was instilled at the end of the procedure and chloramphenicol drops given to take home for 3 days.

\section{Statistical methods}

Retinal vascular calibres (CRAE and CRVE) were assessed as continuous variables. Normality was assessed for all the analyses and appropriate nonparametric methods were applied as necessary. For normally distributed continuous variables, arithmetic means and SDs were calculated. For baseline comparison between study eyes and control eyes, the Pearson's method was used for categorical data, the statistical result being distributed as $\chi^{2}$. For normally distributed continuous variables, Student's $t$-test was used to compare the basic characteristics between the two groups. To assess the change in CRAE and CRVE between baseline and 12 months, the absolute change was assessed using paired $t$-tests.

A multivariate linear regression model was used to access the risk factors for the change in CRAE or CRVE after adjustment for covariates with a univariate significance of $<0.10$. All pertinent variables were examined for correlations and multi-collinearity using Pearson's product-moment correlation. All the statistical analyses were conducted with Stata version 11.0 (Stata
Corp., College Station, TX, USA). A two-tailed $P$-value $<0.05$ was considered statistically significant.

\section{Results}

At baseline, 88 injected eyes and 61 non-injected eyes had gradable images. Of these, 53 injected eyes and 41 noninjected eyes had images available at baseline and 12 months and were considered in the statistical analysis. No differences were seen in eyes included compared with those that were excluded, with respect to CRVE, CRAE CMT, gender, lesion type, history of tobacco use, diabetes, or vascular disease $(P>0.10)$. The majority of patients were women $(63 \%)$ and mean age was 77.5 years (SD 7.3 years). Mean Log MAR visual acuity at baseline was 0.61 (0.50) (Snellen equivalent 20/80), 46.2\% were past or present smokers. Most lesions were non-predominantly classic in nature $(60.8 \%)$.

Mean CRAE was similar within injected and noninjected eyes (144.93 vs $145.74 \mu \mathrm{m}, P=0.80$ ). Similarly, no statistically significant difference was observed with respect to CRVE (216.23 vs $219.91 \mu \mathrm{m}, P=0.53$ ).

\section{Baseline vascular measurements}

Table 1 describes the variation in baseline CRAE and CRVE with eye and patient characteristics. Older age was associated with narrowing of both CRAE (140.12 vs $151.90 \mu \mathrm{m}, P<0.001)$ and CRVE (204.68 vs $232.98 \mu \mathrm{m}$, $P<0.001)$, as was worse baseline vision with respect to CRAE (140.02 vs $152.05 \mu \mathrm{m}, P=0.003)$ and CRVE (210.00 vs $225.27 \mu \mathrm{m}, P=0.04)$. Non-predominantly classic $\mathrm{CNV}$ was associated with CRVE narrowing only (208.27 vs $228.80 \mu \mathrm{m}, P=0.006)$, with only a trend being seen for CRAE $(P>0.10)$. A history of tobacco use was associated with widening of both CRAE (150.55 vs $141.86 \mu \mathrm{m}$, $P=0.02$ ) and CRVE (225.73 vs $211.42 \mu \mathrm{m}, P=0.04$ ).

Among the non-injected eyes, increasing age was also associated with narrowed CRAE (140.22 vs $152.39 \mu \mathrm{m}$, $P=0.006)$, as well as CRVE (211.47 vs $231.43 \mu \mathrm{m}$, $P=0.01)$. Poor baseline vision was only associated with CRAE narrowing (134.12 vs $147.10 \mu \mathrm{m}, P=0.03)$, with only a trend in CRVE (210.37 vs $220.07 \mu \mathrm{m}, P=0.32$ ).

\section{Changes in vascular calibre over 12 months}

Over a 12-month period, retinal venular calibre dilatation occurred in injected eyes (mean CRVE change +5.71 (11.58) $\mu \mathrm{m}, P=0.007)$, with a nonsignificant change within arterioles, $+0.69(14.71) \mu \mathrm{m}, P=0.68$. Among the non-injected eyes, there was significant retinal arteriolar narrowing, $-4.20(7.00) \mu \mathrm{m}, P=0.001$ over 12 months, with a trend for narrowing in venules, $-2.16(11.56) \mu \mathrm{m}$, $P=0.28$. 
Table 1 Baseline characteristics of eyes injected with intravtreal ranibizumab for neovascular age-related macular degeneration and their relation to central retinal artery and vein equivalent

\begin{tabular}{|c|c|c|c|c|}
\hline Characteristics & $C R A E$ & P-value & CRVE & P-value \\
\hline \multicolumn{5}{|l|}{ Age group (years) } \\
\hline$\leq 77$ & $151.90(11.21)$ & \multirow[t]{2}{*}{$<0.001$} & $232.98(22.55)$ & \multirow[t]{2}{*}{$<0.001$} \\
\hline$>78$ & $140.12(14.27)$ & & $204.68(22.62)$ & \\
\hline \multicolumn{5}{|l|}{ Gender } \\
\hline Male & $146.06(14.21)$ & \multirow[t]{2}{*}{0.66} & $223.30(26.04)$ & \multirow{2}{*}{0.13} \\
\hline Female & $144.21(14.45)$ & & $211.75(25.34)$ & \\
\hline \multicolumn{5}{|l|}{ Smoking } \\
\hline No smoking & $141.86(13.19)$ & \multirow[t]{2}{*}{0.02} & $211.42(25.03)$ & \multirow[t]{2}{*}{0.04} \\
\hline Past/current smoker & $150.55(11.95)$ & & $225.73(22.77)$ & \\
\hline \multicolumn{5}{|l|}{ CNV lesion type } \\
\hline Predominantly classic & $147.52(14.22)$ & \multirow[t]{2}{*}{0.30} & $228.80(24.16)$ & \multirow[t]{2}{*}{0.006} \\
\hline Non-predominantly classic ${ }^{a}$ & $143.27(14.23)$ & & $208.27(24.21)$ & \\
\hline \multicolumn{5}{|l|}{ CNV lesion size } \\
\hline$\leq 2 \mathrm{DA}$ & $146.59(15.08)$ & \multirow[t]{2}{*}{0.27} & $216.13(27.85)$ & \multirow[t]{2}{*}{0.89} \\
\hline$>2 \mathrm{DA}$ & $141.13(11.36)$ & & $217.36(16.95)$ & \\
\hline \multicolumn{5}{|l|}{ Hypertension } \\
\hline No & $143.42(14.33)$ & \multirow[t]{2}{*}{0.56} & $212.15(20.90)$ & \multirow[t]{2}{*}{0.39} \\
\hline Yes & $145.89(14.34)$ & & $218.82(28.77)$ & \\
\hline \multicolumn{5}{|l|}{ Diabetes } \\
\hline No & $146.18(13.16)$ & \multirow[t]{2}{*}{0.17} & $219.00(23.46)$ & \multirow[t]{2}{*}{0.09} \\
\hline Yes & $138.54(18.58)$ & & $202.00(34.69)$ & \\
\hline \multicolumn{5}{|l|}{ Vascular disease ${ }^{\mathrm{b}}$} \\
\hline No & $146.02(12.77)$ & \multirow[t]{2}{*}{0.40} & 217.35 (23.99) & \multirow[t]{2}{*}{0.64} \\
\hline Yes & $142.20(17.63)$ & & 213.43 (31.19) & \\
\hline \multicolumn{5}{|l|}{ Baseline vision (Log MAR) } \\
\hline$\leq 0.50(20 / 63)$ & $152.05(9.89)$ & \multirow[t]{2}{*}{0.003} & 225.27 (21.98) & \multirow[t]{2}{*}{0.04} \\
\hline$>0.50(20 / 63)$ & $140.02(14.83)$ & & $210.00(27.02)$ & \\
\hline \multicolumn{5}{|l|}{ Central macular thickness } \\
\hline$\leq 250 \mu \mathrm{m}$ & $149.62(13.86)$ & \multirow[t]{2}{*}{0.09} & $220.89(31.14)$ & \multirow[t]{2}{*}{0.30} \\
\hline$>250 \mu \mathrm{m}$ & $142.09(14.55)$ & & $212.36(25.36)$ & \\
\hline
\end{tabular}

Abbreviations: CRAE, central retinal artery equivalent; CRVE, central retinal vein equivalent; CNV, choroidal neovascularisation; DA, disc areas; Log MAR, logarithm of the minimum angle of resolution.

a Includes minimally classic, occult, retinal angiomatous proliferation, fibrovascular pigment epithelial detachment.

${ }^{\mathrm{b}}$ Includes myocardial infarction, angina, and cerebrovascular accident.

Figure 1 shows the change in CRAE and CRVE in injected eyes compared with non-injected eyes, with and without features of end-stage AMD. In non-injected eyes with end-stage AMD features, a significant arteriolar constriction was observed, - $9.67(7.25) \mu \mathrm{m}$, compared with injected eyes, +0.69 (11.57) $\mu \mathrm{m}, P=0.03$. A similar observation was noted for venules, -8.94 (15.77) $\mu \mathrm{m}$, compared with $+5.78(15.08) \mu \mathrm{m}, P=0.02$, in injected eyes. In non-injected eyes, without late AMD features, trends for arteriolar constriction, $-2.66(6.28) \mu \mathrm{m}$, $P=0.21$, and venular constriction were seen, -0.94 (10.81) $\mu \mathrm{m}, P=0.06$, compared with injected eyes.

Within injected eyes, baseline/change in CMT over 12 months, change in vision over 12 months, age, gender, history of tobacco use, ischaemic heart disease, diabetes, hypertension, and number of injections given during the study had no influence on change in the CRAE or CRVE at 12 months, $P>0.10$. There was an association, however, with type of CNV (CRAE, + 3.01 (11.66) $\mu \mathrm{m}$ vs -2.99 (10.73) $\mu \mathrm{m}, P=0.08$, and CRVE, +9.39 (15.81) $\mu \mathrm{m} v s+0.09$ (12.16) $\mu \mathrm{m}, P=0.03$, in eyes with non-predominantly classic compared with those in predominantly classic lesions, respectively). Better baseline visual acuity ( $\leq 0.50$ Log MAR (Snellen equivalent, 20/63)) was associated with narrowing of CRAE, -2.85 (8.99) $\mu \mathrm{m}$ compared with dilatation in eyes with poor acuity, $+3.12(12.64) \mu \mathrm{m}, P=0.08$. A smaller degree of CRVE widening, +2.10 (13.59) $\mu \mathrm{m} v s+8.32$ (15.76) $\mu \mathrm{m}, P=0.10$, was also noted in eyes with better baseline vision. Table 2 and Figure 2 show the changes in vascular calibre and their relation to vision and CMT over the 12-month study period. There was no significant association between change in CMT and change of CRAE $\left(R^{2}=0.09, P=0.58\right)$ or change in CRVE over the 12 months $\left(R^{2}=0.05, P=0.16\right)$. Similarly, the changes in BCVA did not correlate to the change in CRAE 
$\left(R^{2}=0.001, P=0.85\right)$ or CRVE $\left(R^{2}=0.001, P=0.87\right)$, however, the effects on retinal vessel calibre appear to mirror those of CMT and vision.

A multivariate regression model detailing the affect of baseline and treatment characteristics on change in CRAE and CRVE form baseline to 12 months in injected eyes is shown in Table 3. Age, tobacco use, history of diabetes, type of $\mathrm{CNV}$ and baseline vision, number of injections given, and baseline CMT were included as covariates. Increasing age $(+0.53(+0.15,+1.05) \mu \mathrm{m}$, $P=0.04)$ and reduced baseline CMT $(-0.06(-0.005$, $-0.11) \mu \mathrm{m}, P=0.04)$ were associated with an increase venular calibre. A trend was seen for worse baseline vision to be associated with increased dilatation $(+9.66(-0.30,+19.32) \mu \mathrm{m}, P=0.06)$.

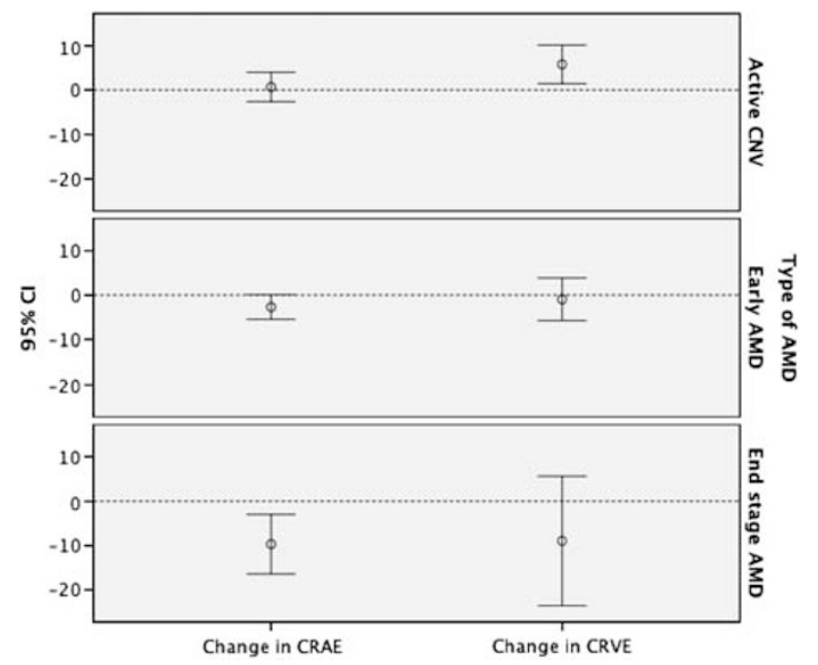

Figure 1 Changes in retinal arteriolar and venular calibre over 12 months, in eyes injected with ranibizumab for choroidal neovascularisation, secondary to age-related macular degeneration and fellow eyes by clinical features of age-related macular degeneration.

\section{Discussion}

In this prospective study, we found that there was no significant difference in retinal vessel calibre in eyes with or without active $\mathrm{CNV}$ at baseline. However, in eyes undergoing repeated treatment with intravitreal ranibizumab for neovascular AMD, there was a significant dilatation of retinal venules. No change was observed in non-injected eyes without late AMD features, whereas eyes with end-stage AMD showed significant constriction of both retinal arterioles and venules. These effects appeared to mirror improvements in CMT and visual acuity.

Our findings contrast findings from previous studies $^{10-12}$ looking at vasculature changes following anti-VEGF treatment in neovascular AMD, where a significant decrease in arteriolar diameter at 3 months and 1 year was seen. These studies, however, had significant limitations, given that only arteriolar calibre was assessed and the lack of a control group. These influences, as well as differences, in the method of vascular calibre assessment and the patient population recruited may account for the difference in results. Our patients had worse baseline visual acuity, Log MAR 0.70 vs 0.49 , a greater percentage of women $(64.2 \%$ vs $36.4 \%)$, as well as a higher percentage of tobacco use $(46.2 \%$ vs $9.1 \%)$, compared with the previous reports. It is also of interest that non-injected eyes showed a significant narrowing in vascular calibre over time, particularly in those eyes with advanced AMD. Thus, it is possible that some of the narrowing observed in the earlier studies may be part of an age-related effect rather than secondary to anti-VEGF treatment. In keeping with this hypothesis, CRAE and CRVE narrowing has been demonstrated with increasing age. ${ }^{24}$

In our study, the underlying reasons for vessel calibre change are unclear. It would appear that in untreated eyes, there is a tendency for retinal arteriolar and venular narrowing with time, especially in eyes with pre-existing

Table 2 Characteristics of eyes treated with intravitreal ranibizumab injections for neovascular age-related macular degeneration over the 12-month study period

\begin{tabular}{lccccc}
\hline & Baseline & 3 months & 6 months & 9 months & 12 months \\
\hline Vision & $0.69(0.39)$ & $0.57(0.41)$ & $0.57(0.41)$ & $0.62(0.44)$ & $0.61(0.45)$ \\
CMT & $316.0(77.1)$ & $227.0(49.4)$ & $240.0(59.4)$ & $243.5(63.0)$ & $242.2(62.0)$ \\
Residual fluid (\%) & N/A & 31.6 & 36.4 & 33.6 & 20.9 \\
Number of injections & N/A & $3.4(0.6)$ & $4.3(1.6)$ & $5.4(2.1)$ & $6.3(2.8)$ \\
CRAE & $144.92(14.24)$ & $144.51(13.59)$ & $147.76(12.90)$ & $143.40(13.03)$ & $145.61(13.13)$ \\
CRVE & $216.23(25.97)$ & $219.83(22.22)$ & $222.50(22.92)$ & $219.97(22.05)$ & $222.02(21.97)$ \\
\hline
\end{tabular}

Abbreviations: CMT, central macular thickness, mean (SD); CRAE, central retinal artery equivalent; CRVE, central retinal vein equivalent; N/A, not applicable.

Vision (Log MAR) value indicates mean (SD) and residual fluid indicates percentage of eyes with residual intraretinal or subretinal fluid based on qualitative assessment of optical coherence tomography scan. 

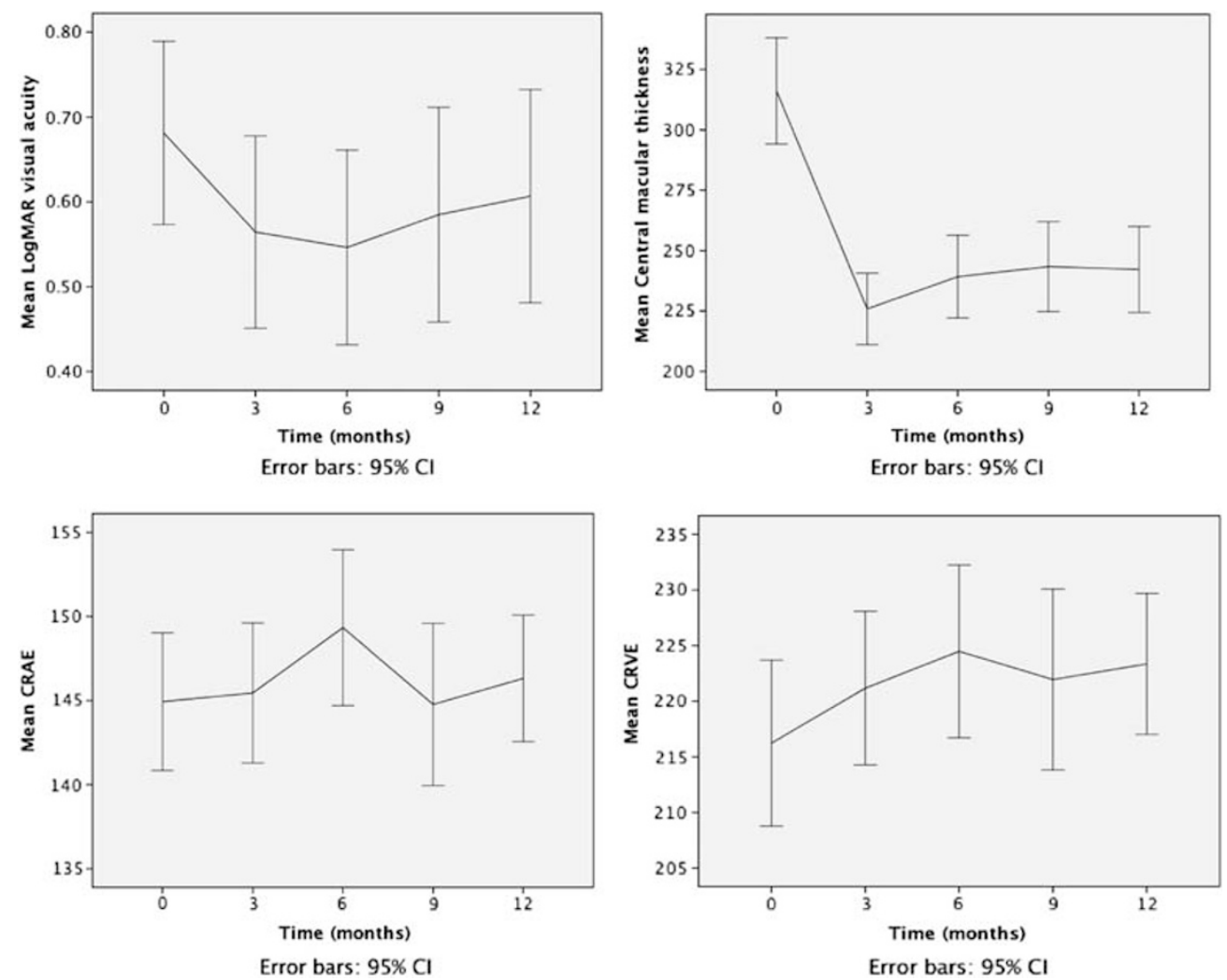

Figure 2 Changes in visual acuity, central macular thickness, and vascular calibre with time in eyes treated with intravitreal ranibizumab for neovascular age-related macular degeneration.

Table 3 Multivariate regression analysis of baseline and treatment factors and their influence on change of central retinal artery and vein equivalent from baseline to 12 months in eyes treated with intravitreal ranibizumab for neovascular agerelated macular degeneration

\begin{tabular}{|c|c|c|c|c|c|c|}
\hline & \multicolumn{3}{|c|}{$C R A E$} & \multicolumn{3}{|c|}{ CRVE } \\
\hline & $\beta$ & $95 \% C I$ & $\mathrm{P}$ & $\beta$ & $95 \% C I$ & $\mathrm{P}$ \\
\hline Age & 0.27 & $-0.19,0.72$ & 0.24 & 0.53 & $0.15,1.05$ & 0.04 \\
\hline Smoking & 2.57 & $-4.12,9.27$ & 0.44 & -2.76 & $-10.30,4.95$ & 0.48 \\
\hline Baseline & 7.42 & $-1.32,16.16$ & 0.09 & 9.66 & $-0.30,19.62$ & 0.06 \\
\hline $\begin{array}{l}\text { Visual } \\
\text { acuity }\end{array}$ & & & & & & \\
\hline Diabetes & -0.88 & $-9.86,8.11$ & 0.84 & -2.11 & $-12.35,8.122$ & 0.68 \\
\hline CNV type & 5.20 & $-2.02,12.41$ & 0.15 & 4.60 & $-3.20,13.18$ & 0.23 \\
\hline $\begin{array}{l}\text { Baseline } \\
\text { CMT }\end{array}$ & -0.02 & $-0.07,0.03$ & 0.34 & -0.06 & $-0.11,-0.005$ & 0.04 \\
\hline $\begin{array}{l}\text { Number of } \\
\text { injections }\end{array}$ & 0.34 & $-0.74,1.42$ & 0.53 & 0.44 & $-0.79,1.67$ & 0.47 \\
\hline
\end{tabular}

Abbreviations: CI, confidence interval; CNV, choroidal neovascularisation.

Age (years), reference group for categorical variables is absence of condition; smoking includes past or present smokers, CNV type comprises predominantly classic (reference group) and non-predominantly classic.

severe macular disruption, whereas in treated eyes, a dilatational effect, especially in venules, is seen. As far as this latter observation is concerned, there are several potential causes. First, there may be a simple correlation with the improvement in macular anatomy as a consequence of retinal thinning with anti-VEGF use. Reduction in macular swelling (intraretinal oedema/ subretinal fluid) may lead to improved perfusion of the retinal vessels, possibly due to a relief of mechanical congestion. Consistent with this hypothesis, eyes with macular oedema secondary to retinal vein occlusion, there is a correlation between increases in retinal thickness and reduced retinal blood flow. ${ }^{25,26}$ A second possibility exists with the possibility that anti-VEGF therapy may have vasoactive effects on the retinal circulation, with secondary local improvement of retinal blood flow. In our study population, although not significantly different, baseline CRAE and CRVE were narrower among the injected eyes with active $\mathrm{CNV}$, compared with non-injected eyes. Following treatment, both the mean CRAE and CRVE were similar in both injected and non-injected eyes. AMD has been linked to ischaemia and hypoxia within the choroid. It has also been shown that both central retinal artery perfusion ${ }^{27}$ and foveolar choroidal blood flow are reduced in patients with AMD. ${ }^{1,2}$ Thus, it is possible that anti-VEGF treatment may 'normalise' blood flow. Third, although 
unlikely, inflammation secondary to the injections themselves or the anti-VEGF drug may be a possible cause. In both the MARINA and ANCHOR trials, ${ }^{4,5}$ as well as other case series, ${ }^{28,29}$ a small proportion of patients presented with acute uveitis. This may be due to a systemic immune response, ${ }^{30}$ possibly related to the formation of anti-ranibizumab antibodies. These antibodies have previously been demonstrated and their presence correlates with the number of treatments given. ${ }^{5}$ In this study, however, we found no correlation between the changes in retinal vasculature and the number of treatments given. Finally, retinal venular widening may reflect a possible ischaemic effect. ${ }^{14,31-33}$ Retinal venular calibre widening may be a risk marker for stroke, particularly haemorrhagic stroke. ${ }^{34-36}$ It has been suggested that the inhibition of VEGF by anti-VEGF drugs may also increase the risk of non-ocular haemorrhage, ${ }^{35,37}$ possibly as a consequence of systemic distribution of these drugs following intraocular delivery. Changes in retinal venular calibre have been linked with stroke, reflecting systemic changes in blood flow, inflammation, and endothelial function. ${ }^{14,15}$ Thus, it is possible that the improvements in CMT and vision with anti-VEGF treatment mask potential deleterious effects of VEGF blockade.

With respect to the decrease in vessel calibre in the non-injected eyes with end-stage AMD, it is possible that this may be a consequence of irreversible damage to the retinal elements. Thus, decreased metabolic activity within the macula secondary to outer retinal damage may reduce the demand for retinal blood flow, with vascular constriction as a consequence.

The main weakness of our study was that only around $70 \%$ of the patients initially recruited had adequate quality photographs for the image-analysis software to determine retinal vascular calibre, with significant attrition through the 12-month follow-up period. This led to a relatively small size, which may be a criticism of our results. There were, however, no significant differences in CRAE, CRVE, and CMT in study eyes of those included in the analysis compared with those excluded. Another potential weakness of our study is the lack of standardised treatment protocol, with 'as required' dosing allowed to maintain a 'fluid-free' macula, rather than monthly dosing as seen in the pivotal randomised controlled trials. It is possible that monthly treatment may have influenced outcome. Finally, at baseline, although most grading photographs were taken on immediately prior to the first anti-VEGF injection, some were taken up to $48 \mathrm{~h}$ prior to this first treatment. This may have influenced the baseline measurements, however, the effects of venular widening were also seen beyond the baseline to 3-month period, suggesting that this was not a major contributor to our findings.

In conclusion, our prospective study shows that in eyes with neovascular AMD, there is a significant dilatation in retinal venular calibre following repeated intravitreal injections of ranibizumab. Although the underlying mechanisms of these changes are unclear, this may be due to anatomic improvement within the macula or a normalisation of retinal vascular calibre secondary to relief of ischaemia and restoration of retinal blood flow.

\section{Summary}

What was known before

- Anti-VEGF agents are commonly used in the treatment of AMD.

- Little is known as to the potential beneficial or deleterious vasoactive effects of these compounds.

- There is concern as to the effect of these drugs on the development of vascular disease such as stroke and ischaemic heart disease.

- Previous small, non-controlled studies have shown retinal arteriolar narrowing with anti-VEGF treatment, possibly as a result of ischaemia.

What this study adds

- This study contradicts the previous findings, showing a retinal venular dilatation with repeated anti-VEGF treatment, with little change in arterioles. These changes mirror improvements in macular thickness and vision. This may suggest a local reason for the dilatation.

- In nontreated eyes with end-stage AMD, narrowing of both arterioles and venues were observed, possibly as a result of reduced metabolic activity.

\section{Conflict of interest}

Dr Wickremasinghe was supported by a Novartis fellowship during the 2008/9 period. The remaining authors declare no conflict of interest.

\section{Acknowledgements}

This study was partially funded by a National Health and Medical Research Council grant, 52993. Drs Guymer and Wong are on advisory boards of Novartis and Pfizer and have received research funding, speaking fees, travel and accommodation from either/both companies. The Centre for Eye Research Australia receives Operational Infrastructure Support from the Victorian Government. This study was approved by the Human Research and Ethics Committee of the Royal Victorian Eye and Ear Hospital (RVEEH).

\section{Author contributions}

SW, SQ, and TW designed and conducted the study. SW collected the data. SW and RG managed the data. Analysis was done by JX and RK; interpretation of the data was done by SW, RG, TW, and SQ; and preparation by SW, TW, and RG. Review or approval of the manuscript was done by RG, TW, and SQ. 


\section{References}

1 Grunwald JE, Metelitsina TI, Dupont JC, Ying GS, Maguire MG. Reduced foveolar choroidal blood flow in eyes with increasing AMD severity. Invest Ophthalmol Vis Sci 2005; 46(3): 1033-1038.

2 Grunwald JE, Hariprasad SM, DuPont J, Maguire MG, Fine SL, Brucker AJ et al. Foveolar choroidal blood flow in age-related macular degeneration. Invest Ophthalmol Vis Sci 1998; 39(2): 385-390.

3 Kwak N, Okamoto N, Wood JM, Campochiaro PA. VEGF is major stimulator in model of choroidal neovascularization. Invest Ophthalmol Vis Sci 2000; 41(10): 3158-3164.

4 Brown DM, Kaiser PK, Michels M, Soubrane G, Heier JS, Kim RY et al. Ranibizumab versus verteporfin for neovascular age-related macular degeneration. $N$ Engl J Med 2006; 355(14): 1432-1444.

5 Rosenfeld PJ, Brown DM, Heier JS, Boyer DS, Kaiser PK, Chung CY et al. Ranibizumab for neovascular age-related macular degeneration. $N$ Engl J Med 2006; 355(14): 1419-1431.

6 Kabbinavar F, Hurwitz HI, Fehrenbacher L, Meropol NJ, Novotny WF, Lieberman G et al. Phase II, randomized trial comparing bevacizumab plus fluorouracil (FU)/leucovorin (LV) with FU/LV alone in patients with metastatic colorectal cancer. J Clin Oncol 2003; 21(1): 60-65.

7 Eremina V, Jefferson JA, Kowalewska J, Hochster H, Haas $\mathrm{M}$, Weisstuch $\mathrm{J}$ et al. VEGF inhibition and renal thrombotic microangiopathy. N Engl J Med 2008; 358(11): 1129-1136.

8 Kamba T, Tam BY, Hashizume H, Haskell A, Sennino B, Mancuso MR et al. VEGF-dependent plasticity of fenestrated capillaries in the normal adult microvasculature. Am J Physiol Heart Circ Physiol 2006; 290(2): H560-H576.

9 Choi YI, Lee SH, Ahn BK, Baek SU, Park SJ, Kim YS et al. Intestinal perforation in colorectal cancers treated with bevacizumab (Avastin). Cancer Res Treat 2008; 40(1): 33-35.

10 Papadopoulou DN, Mendrinos E, Mangioris G, Donati G, Pournaras CJ. Intravitreal ranibizumab may induce retinal arteriolar vasoconstriction in patients with neovascular agerelated macular degeneration. Ophthalmology 2009; 116(9): 1755-1761.

11 Mendrinos E, Mangioris G, Papadopoulou D, Donati G, Pournaras $C$. One year results of the effect of intravitreal ranibizumab on the retinal arteriolar diameter in patients with neovascular age-related macular degeneration. Invest Ophthalmol Vis Sci 2009; e-pub ahead of print 23 September 2009; doi:10.1167/iovs.09-3721.

12 Fontaine O, Olivier S, Descovich D, Cordahi G, Vaucher E, Lesk MR. The effect of intravitreal injection of bevacizumab on retinal circulation in patients with neovascular macular degeneration. Invest Ophthalmol Vis Sci 2011; 52: 7400-7405.

13 Sun C, Wang JJ, Mackey DA, Wong TY. Retinal vascular caliber: systemic, environmental, and genetic associations. Surv Ophthalmol 2009; 54(1): 74-95.

14 Wong TY, Islam FM, Klein R, Klein BE, Cotch MF, Castro C et al. Retinal vascular caliber, cardiovascular risk factors, and inflammation: the multi-ethnic study of atherosclerosis (MESA). Invest Ophthalmol Vis Sci 2006; 47(6): 2341-2350.

15 Nguyen TT, Islam FM, Farouque HM, Klein R, Klein BE, Cotch MF et al. Retinal vascular caliber and brachial flowmediated dilation: the multi-ethnic study of atherosclerosis. Stroke 2010; 41(7): 1343-1348.
16 Wong TY, Klein R, Islam FM, Cotch MF, Folsom AR, Klein BE et al. Diabetic retinopathy in a multi-ethnic cohort in the United States. Am J Ophthalmol 2006; 141(3): 446-455.

17 ETDRS report number 10. Early Treatment Diabetic Retinopathy Study Research Group. Grading diabetic retinopathy from stereoscopic color fundus photographsan extension of the modified Airlie House classification. Ophthalmology 1991; 98(5 Suppl): 786-806.

18 Hubbard LD, Brothers RJ, King WN, Clegg LX, Klein R, Cooper LS et al. Methods for evaluation of retinal microvascular abnormalities associated with hypertension/ sclerosis in the Atherosclerosis Risk in Communities Study. Ophthalmology 1999; 106(12): 2269-2280.

19 Wong TY, Knudtson MD, Klein R, Klein BE, Meuer SM, Hubbard LD. Computer-assisted measurement of retinal vessel diameters in the Beaver Dam Eye Study: methodology, correlation between eyes, and effect of refractive errors. Ophthalmology 2004; 111(6): 1183-1190.

20 Knudtson MD, Lee KE, Hubbard LD, Wong TY, Klein R, Klein BE. Revised formulas for summarizing retinal vessel diameters. Curr Eye Res 2003; 27(3): 143-149.

21 Aiello LP, Brucker AJ, Chang S, Cunningham ET Jr, D'Amico DJ, Flynn HW Jr et al. Evolving guidelines for intravitreous injections. Retina 2004; 24(5 Suppl): S3-S19.

22 Holz FG, Amoaku W, Donate J, Guymer RH, Kellner U, Schlingemann RO et al. Safety and efficacy of a flexible dosing regimen of ranibizumab in neovascular age-related macular degeneration: the SUSTAIN study. Ophthalmology 2011; 118(4): 663-671.

23 Fung AE, Lalwani GA, Rosenfeld PJ, Dubovy SR, Michels S, Feuer WJ et al. An optical coherence tomography-guided, variable dosing regimen with intravitreal ranibizumab (Lucentis) for neovascular age-related macular degeneration. Am J Ophthalmol 2007; 143(4): 566-583.

24 Leung H, Wang JJ, Rochtchina E, Tan AG, Wong TY, Klein R et al. Relationships between age, blood pressure, and retinal vessel diameters in an older population. Invest Ophthalmol Vis Sci 2003; 44(7): 2900-2904.

25 Noma H, Funatsu H, Sakata K, Harino S, Nagaoka T, Mimura $\mathrm{T}$ et al. Macular microcirculation and macular oedema in branch retinal vein occlusion. $\mathrm{Br} J$ Ophthalmol 2009; 93(5): 630-633.

26 Horio N, Horiguchi M. Effect of arteriovenous sheathotomy on retinal blood flow and macular edema in patients with branch retinal vein occlusion. Am J Ophthalmol 2005; 139(4): 739-740.

27 Ciulla TA, Harris A, Chung HS, Danis RP, Kagemann L, McNulty L et al. Color Doppler imaging discloses reduced ocular blood flow velocities in nonexudative age-related macular degeneration. Am J Ophthalmol 1999; 128(1): 75-80.

28 Wickremasinghe SS, Michalova K, Gilhotra J, Guymer RH, Harper CA, Wong TY et al. Acute intraocular inflammation after intravitreous injections of bevacizumab for treatment of neovascular age-related macular degeneration. Ophthalmology 2008; 115(11): 1911-1915.

29 Wu L, Martinez-Castellanos MA, Quiroz-Mercado H, Arevalo JF, Berrocal MH, Farah ME et al. Twelve-month safety of intravitreal injections of bevacizumab (avastin): results of the Pan-American Collaborative Retina Study Group (PACORES). Graefes Arch Clin Exp Ophthalmol 2008; 246(1): 81-87.

30 Forooghian F, Cukras C, Meyerle CB, Chew EY, Wong WT. Tachyphylaxis after intravitreal bevacizumab for exudative 
age-related macular degeneration. Retina 2009; 29(6): 723-731.

31 Couillard C, Ruel G, Archer WR, Pomerleau S, Bergeron J, Couture $\mathrm{P}$ et al. Circulating levels of oxidative stress markers and endothelial adhesion molecules in men with abdominal obesity. J Clin Endocrinol Metab 2005; 90(12): 6454-6459.

32 Caballero AE. Metabolic and vascular abnormalities in subjects at risk for type 2 diabetes: the early start of a dangerous situation. Arch Med Res 2005; 36(3): 241-249.

33 Klein R, Klein BE, Knudtson MD, Wong TY, Tsai MY. Are inflammatory factors related to retinal vessel caliber? The Beaver Dam Eye Study. Arch Ophthalmol 2006; 124(1): 87-94.
34 Wieberdink RG, Ikram MK, Koudstaal PJ, Hofman A, Vingerling JR, Breteler MM. Retinal vascular calibers and the risk of intracerebral hemorrhage and cerebral infarction: the Rotterdam Study. Stroke 2010; 41(12): 2757-2761.

35 Gillies MC, Wong TY. Ranibizumab for neovascular agerelated macular degeneration. $N$ Engl J Med 2007; 356(7): 748-749; author reply 49-50.

36 Ueta T, Yanagi Y, Tamaki Y, Yamaguchi T. Cerebrovascular accidents in ranibizumab. Ophthalmology 2009; 116(2): 362.

37 Schmucker C, Ehlken C, Hansen LL, Antes G, Agostini HT, Lelgemann M. Intravitreal bevacizumab (Avastin) vs. ranibizumab (Lucentis) for the treatment of age-related macular degeneration: a systematic review. Curr Opin Ophthalmol 2010; 21(3): 218-226. 